\title{
Assessment and Professors' Competence in Italian Higher Music Education between Tradition and New Goals
}

\author{
Tiziana Rossi' ${ }^{1}$ Anna Maria Bordin², Dario De Cicco ${ }^{3}$ \\ ${ }^{1}$ Conservatory of Music, Parma, Italy \\ ${ }^{2}$ Conservatory of Music, Pavia, Italy \\ ${ }^{3}$ Conservatory of Music, Turin, Italy \\ Email: tiziana.rossi@conservatorio.pr.it, annamariabordin@gmail.com, dariodecicco@alice.it
}

Received 2 July 2014; revised 4 August 2014; accepted 12 August 2014

Copyright (C) 2014 by authors and Scientific Research Publishing Inc.

This work is licensed under the Creative Commons Attribution International License (CC BY). http://creativecommons.org/licenses/by/4.0/

(c) (i) Open Access

\begin{abstract}
Assessment of learning and the allocation of credits according to the European Credit Transfer and Accumulation System is no longer an educational tool which concerns professors, but it has become a statutory duty that sees conservatories of music part of a network of relationships. This study highlights the situation of Higher Music Education in Italy: we will consider the assessment models in their context of use and on the basis of ideal values that support them; we will examine the famous case of Giuseppe Verdi, rejected in its entrance exam to the Conservatory of Milan, which represents, paradoxically, the weaknesses of the assessment system, providing a historical perspective; we will propose an examination of the practical and legal aspects of the national assessment system; finally, we will offer an example of good practice that shows how to contextualize some important aspects of this problem.
\end{abstract}

\section{Keywords}

Italian Higher Music Education, Assessment, Professors' Competence, Giuseppe Verdi

\section{Introduction}

As students we may have sometimes wondered: if I had been assessed better, would I be a better musician? Did being assessed contribute to my personal and artistic realization, and to reaching an awareness of my musical identity?

If the answers were both curtly negative, there would be some dread of the uselessness of assessment since it

How to cite this paper: Rossi, T., Bordin, A. M., \& De Cicco, D. (2014). Assessment and Professors' Competence in Italian Higher Music Education between Tradition and New Goals. Creative Education, 5, 1341-1352. 
would be neither a cause of success nor lack of success whether in the world of work or in personal life.

And as teachers we might also wonder: does assessment in higher musical education really result in efficient teaching? Or is it an activity that is instrumental to an academic training course for the student that has its beginning, its development and its end, and that imposes specific tasks on the professor?

This report investigates the stages in assessing students who intend to become involved in music education at the highest level, in terms of:

1) initial assessment when the student is undertaking specialist music training,

2) intermediate assessment when the student is developing through different types of training, a preparation that will allow access to the concrete world of work with its various employment opportunities, and

3) final assessment when the student is demonstrating the final high level of ability attained.

To understand the present situation in Italian Higher Music Education, it is necessary to focus on the regulatory profile in virtue of the Italian Law 508/1999, which restructured Italian Conservatories by developing rules and customs to assess multiple skills through initial, intermediate and final examinations that demonstrate the expected predisposition and musical competence.

The syllabus of musical studies in Conservatories was profoundly revamped by standardizing a myriad courses previously divided into inhomogeneous periods involving the necessity for bridging courses and/or other obstacles between the various curricula (e.g. harpsichord after piano, viola after violin, conducting after composition, didactics only after completion of training cycles to study an instrument).

The new regulations envisage a vaster theoretical and cultural education that will prove useful to undertake different professional avenues in the field of music.

The syllabus is structured to include all instrumental and musical specialities in the initial three-year course and the subsequent two-year one. It is measured in academic training credits awarded following the passing of many exams and by recognition of activities deemed formative according to the Bologna Process.

Consequently, new relationships of correlation and functional interdependence have been established in the act of assessing, and this is even before modifying the professional awareness of the musician as teacher who is now invested with teaching tasks that were hitherto inconceivable (Fautley, 2010).

Here we shall look at assessment models that are interdependent on learning models and the ideal values that inspire these; we shall look at the famous case of Giuseppe Verdi failing his entry exam to the Conservatory of Milan, opening a historical perspective on the problem of assessment in Italy, not so much because of the event, but because of the evidences that Verdi himself left us in his letters; we shall consider an investigation into assessment in music Conservatories in its legal and practical aspects; lastly, we shall provide an example of an experience of good teaching practice where reflections on the themes dealt with can be seen applied.

\section{Assessment Model and Training Model}

Assessment of learning and the subsequent allocation of credits according to the European Credit Transfer and Accumulation System in European countries (Döbert, von Kopp, \& Mitter, 2007; Cox, 2010; Eurydice, 2010), is no longer an educational tool or duty that concerns only the Conservatory professor, or team of professors, on the basis of agreed criteria, but has become a statutory task that sees the individual Conservatory of music as part of a network of relationships and comparisons.

The ECTS system has led to indisputable advantages for the international validation of qualifications, student mobility, the possibility of agreed conventions between Conservatory and University to develop joint courses or to harmonize the double attendance of students who intend to study music at the highest levels without abandoning other university studies or, again, to allow exchange of professors under contract.

Nonetheless, the limits of this new formal objectivity are also evident as regards the competence of the professor, who may be assessing with new tools but with a mentality that is unchanged with respect to the past.

A new organisational model cannot express a changed educational model also in higher musical education without changing its players and what is demanded of them.

In this period of complex transition from the old system to the new system, we are seeing a growing gap between Conservatory professors: between those who have voluntarily been able to connect with the change in perspective and those who have remained at a standstill in the face of a lack of training and a mandatory update by the central administration regarding the teaching tasks of a musician as teacher. 
This study, as part of the debate on academic teaching, highlights the situation of Higher Music Education in Italy: to increase the effectiveness of teaching/learning and the quality of the results achieved by the students, it is necessary to improve the teaching skills_-and here particularly that of assessment—of Conservatory professors; musicians who teach musicians and trainers of trainers (Rossi, 1997, 2010).

\section{Art and Science Are Free and So Is the Teaching of Them}

At the base of the professionalism of teachers current legislation gives freedom in teaching as a postulate corresponding to that of the concept of freedom inherent in art and science, since they cannot help relying on themselves.

It is Article 33 of the Italian Constitution—ratified by the Constituent Assembly in 1947 as part of the set of democratic principles and values adopted for the new sovereign state- that fixes the principle in ideal terms: freedom in teaching gradually emerged updating itself as instrumental to the complete training of students, to the right to study, to respect for freedom of thought, and, in the light of the individual and collective responsibility of teachers in providing a public service, substantiating itself in the didactic autonomy and free cultural expression of each teacher, without limitations of a political, religious or ideological order. Freedom in teaching no longer constituted a principle of absolute order but a strictly functional professional prerogative.

Also the Italian Law 508/99 to reform the national musical education system conforms to Article 33 of the Constitution assuming its principles of freedom in teaching and self-determination, within a system of obviously impassable national laws, in teaching activities, in research, as well as in scientific and artistic production.

Our constitutional right finds supranational correspondence in Article 13 of the fundamental Charter of Rights of the European Union, promulgated in Nice on 7 December, 2000: Art and Scientific Research are Free; Academic Freedom is Respected.

Science and Art per se cannot help being free and, consequently, the need to safeguard this freedom is essential for artistic and scientific manifestations as well as thought.

Assessment must be considered with regard to the exercising of this "freedom" by Conservatory professors, occupying as they do such a substantial part of educational and teaching activities at all levels of training.

\section{An excellent Failure: Giuseppe Verdi!}

The history of assessment in higher musical education has not yet been written, however everyone knows the famous story of Giuseppe Verdi being "failed". This failure may have come about not because the Commission had misunderstood the capacities of the young man from Busseto, but because the conditions envisaged by the regulations did not exist.

Also Giuseppe Verdi's life in his formative years was interwoven with entry exams, regulations and assessment procedures to be shared and demonstrated. There is always the possibility of errors and misunderstandings but the position of those making the assessment must be free from any doubt.

In effect, the Commission who assessed Verdi considered him over age (he was 18 while the maximum age allowed for entry was 14) and also deemed the position of his hand on the piano to be incorrect. In addition he was a "foreigner", coming as he did from the Duchy of Parma.

From the Commission's minutes we can read:

[...] Verdi would need to change the position of his hand, [something which], at the age of 18 would be difficult [...]. As for the compositions he has presented as his own, by applying himself with care and patience to cognition of the rules of counterpoint, he could direct the imagination he has shown to possess, and thereby plausibly achieve success in composition. (Conati, 2000: p. 371 note 2)

Only Alessandro Rolla, an illustrious violinist and member of the Commission, expressed a favourable opinion that Verdi be admitted to the Conservatory.

With regard to this question, in a letter to Jacopo Caponi, dated 13 October 1880, Verdi commented:

My Dearest Caponi,

Not in 1833, but in 1832 in the month of June (I was not yet 19 years old) I made a request in writing to be admitted as a paying student at the Conservatory of Milan. In addition, I underwent a kind of exam at the Conservatory by presenting some of my compositions, and playing a piece on the pianoforte in front of Basily, Piantanida, Angeleri and others, etc., plus old Rolla, whom I had been recommended to by my 
maestro at Busseto, Ferdinando Provesi. Around eight days later, I took myself to Rolla who said to me: Forget the Conservatory: choose a maestro in the city: I recommend Lavigna or Negri. I heard nothing more from the Conservatory. No reply to my request.

No one spoke to me, neither before, nor after the exam, of the Regulations.

And I know nothing of the assessment of Basily as reported by Fétis.

That's all!

I have written to you hastily, and briefly, because you are short of time.

However, I have told you everything I know.

(Pougin, 1881: p. 140; Walker, 1962: p. 15; Gatti, 1931: p. 48; Oberdorfer, 1951: p. 86)

For Verdi, this failure represented such an affront that in 1900 he refused to have the Conservatory of Milan named after him. A dedication to this musical genius, loved all over the world, would not come until later.

When, as a mature and respected musician, he had to give his views on the effectiveness of teaching in one Italian Conservatory, he focused his attention on the lack of rules and norms:

There were no teaching norms in the old Naples Conservatory directed by Durante and Leo. They themselves developed the methods to be followed; their methods in some ways differed from one to the other, but both were good. Not even later under Fenaroli, who left his figured bass exercises [...] were teaching norms established. (Letter from Verdi to the Minister Correnti of 2 February 1871; cf. Montemorra Marvin, 2010: pp. 168-169).

He expressed with great clarity the need to provide Italian Institutes not only with good rules, but also with teachers and directors that could understand these deeply, and would undertake to respect them:

I am convinced that a Commission cannot reform the Conservatories. Even once we had drawn up the best regulations for teaching (always supposing that this is possible), what would we have accomplished? Nothing!

If the director is a learned man, he will have no need for our rules. If he is not, he will make neither head nor tail of them and will do nothing about it. (Letter from Verdi to Giulio Ricordi of January 1871; Montemorra Marvin, 2010)

Nevertheless, in drawing up the Regulations for the Royal Music Conservatories in Italy (1871), when Verdi was nominated Chairman of the Commission for the reform of musical studies, as regards entrance exams no specific parameters were to be found — albeit requested — to verify musical aptitude on entry (Avanzini, 2002).

If the story of Verdi has more of the ring of an anecdote, it can instead be read by educational specialists as emblematic of the limits of assessment being able to predict artistic success, but equally emblematic of the limits of the capacity to accept those who fail exams.

Assessors in higher musical education are required to have artistic sensibility in order to recognize the artistic/ musical value of the candidate both in its more original forms and its more usual ones. The nature of this artistic sensibility has confines to be investigated but, at the moment of the assessment, there must be other guiding principles: correctness, consistency and fairness; and this must be clearly revealed in practice based on procedures that guarantee transparency also as regards students' expectations to receive information on the motives that lie behind assessments (Ausubel, 1983; Cox, 2010).

\section{Results of the Investigation into Assessment between Regulations and Practice}

To find out how Italian Higher Music Education is managing procedures to assess students in the transition phase, we:

a) considered teaching regulations and exam programmes from a sample of 20 Conservatories located in regional capitals by means of documentation accessible online on institutional sites;

b) considered opinions on experience as assessors in a sample of 88 professors from 13 Conservatories, using an anonymous questionnaire, as part of a wider-ranging investigation that involved 268 music teachers at various levels of education (Bordin, Cantamessa, \& De Cicco, 2011).

What emerged is a dynamic situation that nonetheless seeks to optimize the system, whose visibility has introduced clarity and the comparability of standard practices. Non-stop monitoring from the bottom up - of both practices and mentality—-would clarify the direction of the changes in genuine progress or in involutions. 
In virtue of the regulations dictated by the general norms and those adopted autonomously, teaching regulations discipline the carrying out of training activities but also assessment and-for the 20 Conservatories considered-provide the following homogeneous indications with regard to intermediate and final exams:

1) Definition of the type of assessment: practical (performance or written) and/or oral exams; while further specifications can be given by Departments and/or the professors in charge of the course (e.g. in particular cases verification of performance may be made in groups guaranteeing however the assessability of individual contributions);

2) Definition of an assessment scale: out of thirty for intermediate exams and out of one hundred for the final one. Exams are passed with a minimum mark of 18 out of 30 while full marks can unanimously receive a commendation. (For entry exams the assessment can be expressed out of ten, out of thirty, or a simple verdict of eligibility may be given with the awarding of pass-list points to fill available places);

3) Definition of assessment Commissions: the number of professors who make up the Commissions, disciplinary characterization of the professors, the function of the Commission chairman;

4) Definition of administrative procedures: bureaucratic and time requirements to be respected for both candidates and professors;

5) Definition of the contents of the exams: referred to the Departments and/or professors in charge of courses;

6) Definition of the awarding of the mark: for the awarding of the final mark only, there are precise procedures referring to the weighted average, and there are also indications of the influence of the various parts of the exam on the overall mark, in particular concerning the submission of a written thesis.

Instead, we find diversified indications among Conservatories-in programmes monitored up until $28 \mathrm{Fe}-$ bruary 2013 on the institutional sites_-regarding the assessment of knowledge and the ability at entry during exams to attend study courses, at both First and Second Level.

Courses that are increasingly diversified continuously implement the offer of professionalizing music courses that has appeared in the last decade which sees professors involved in more sophisticated procedural aspects with respect to the past but that are still characterized by discontinuity and randomness.

In First Level academic courses, it can happen that with regard to the most used indicators in terms of percentage (specific disciplinary skills and general culture and/or motivational competence) we find precise indications or absence of notable indications as expressed below and shown in the graphs summarizing the data collected that also show less frequently considered indicators (sigh treading, score reading, technical-theoreticalanalytical skills, perceptive/rhythmic skills, intonation and the writing of music, historical knowledge, training and professional curricula):

- in the area of interpretative disciplines (musical instrument/singing) performance skill data was available in $80 \%$ of the Institutions with general culture and/or motivational competence in $40 \%$ (Figure 1(a));

- in the area of compositional disciplines compositional skill data was available in $60 \%$ of the Institutions with general culture and/or motivational competence in the curriculum in $40 \%$ of the Institutions (Figure $1(b))$;

- in the area of electronic music and sound technology compositional skill data was available in $45 \%$ of the Institutions with behavioural/motivational competence in 45\% (Figure 1(c));

- in the area of teaching disciplines performance skill data was available in $60 \%$ of the Institutions with general culture and/or motivational competence in 50\% (Figure 1(d)).

In Second Level academic courses:

- in the area of interpretative disciplines (musical instrument/singing) performance skill data was available in $65 \%$ of the Institutions with general culture and/or motivational competence in 30\% (Figure 2(a));

- in the area of compositional disciplines compositional skill data was available in 50\% of the Institutions with general culture and/or motivational competence in 35\% (Figure 2(b));

- in the area of electronic music and sound technology compositional skill data was available in $60 \%$ of the Institutions with general culture and/or motivational competence in 35\% (Figure 2(c));

- in the area of teaching/instrument disciplines - the only real news and exception from this academic yearthe entry exam is the same for all Institutions because it is regulated by ad hoc national regulations that aim to fix quotas for candidates at a national level. Skills in Italian language, history, and musical theory were assessed by a preliminary written test that bars access to practical exams to check performance skills on the instrument and to oral exams to check analytical skills; assessment of the candidate's curriculum only comes into play after passing all the exams. No importance is given to motivational/behavioural aspects (Figure 2(d)). 


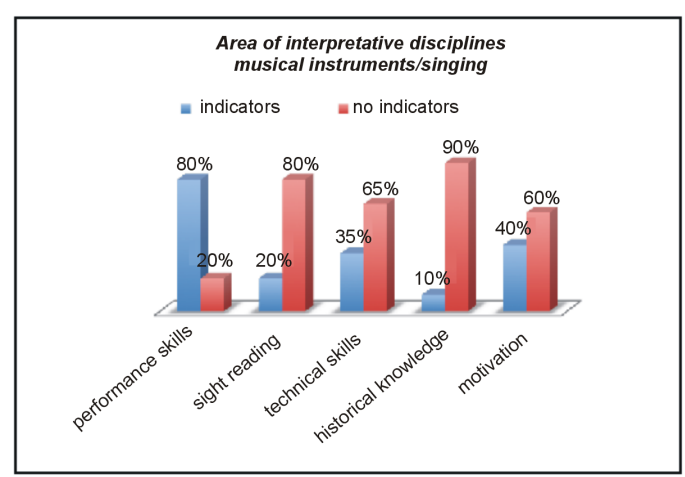

(a)

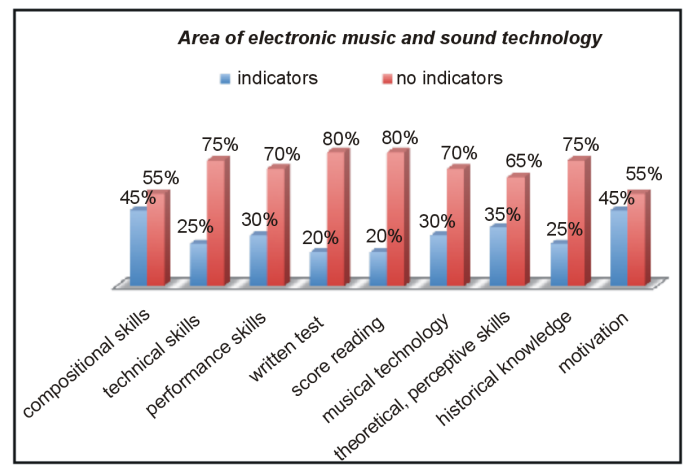

(c)

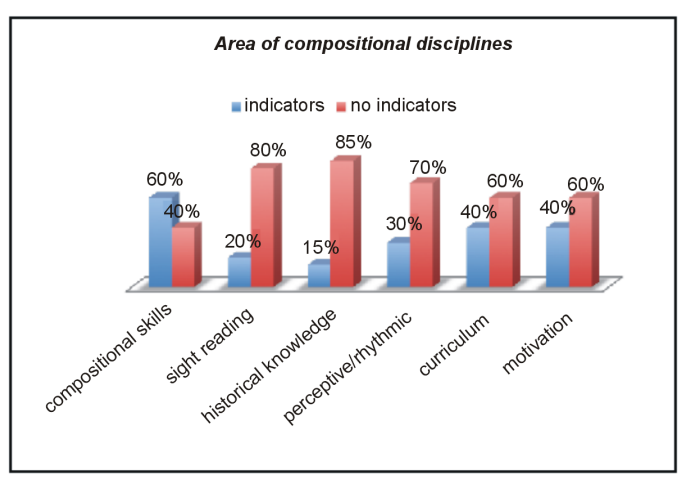

(b)

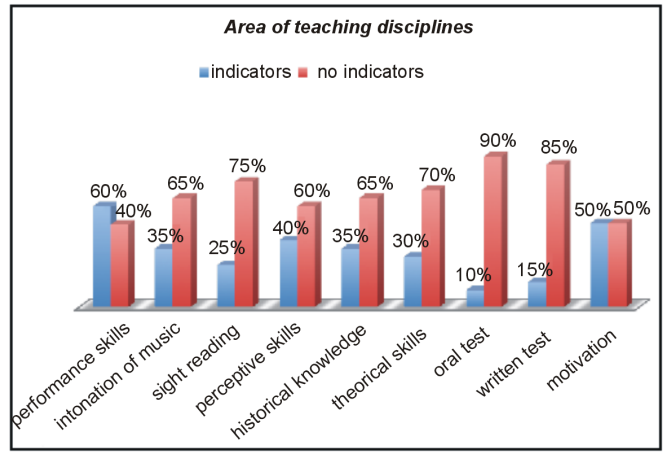

(d)

Figure 1. Entry exams in first level academic courses.

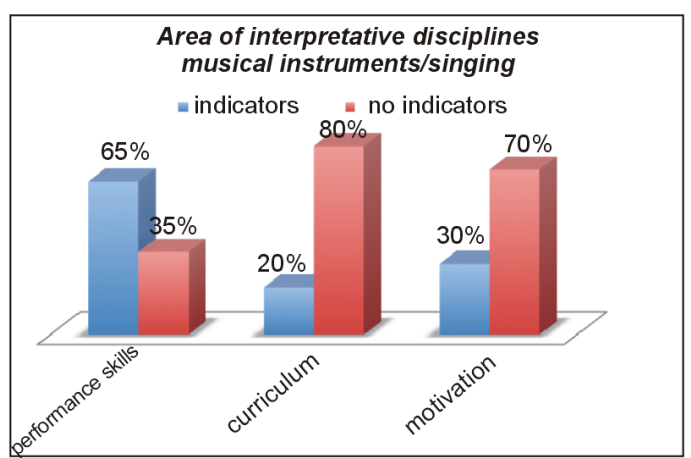

(a)

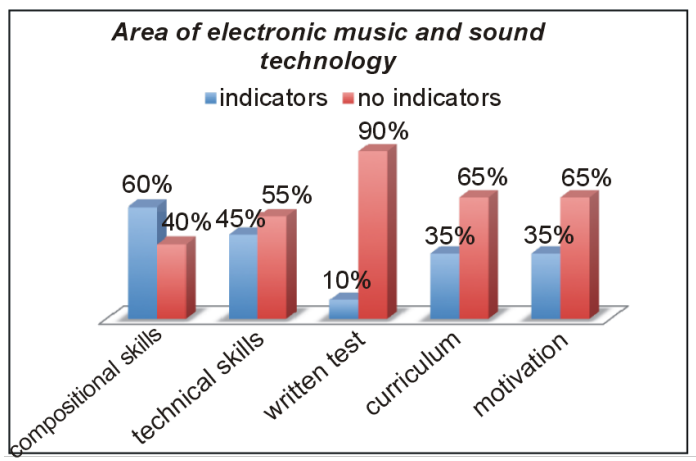

(c)

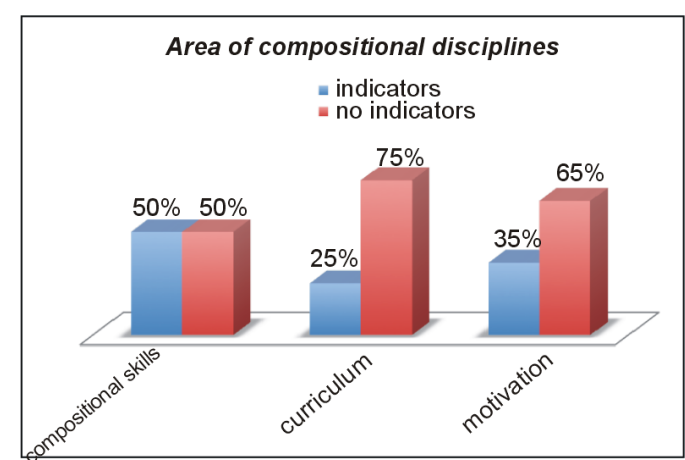

(b)

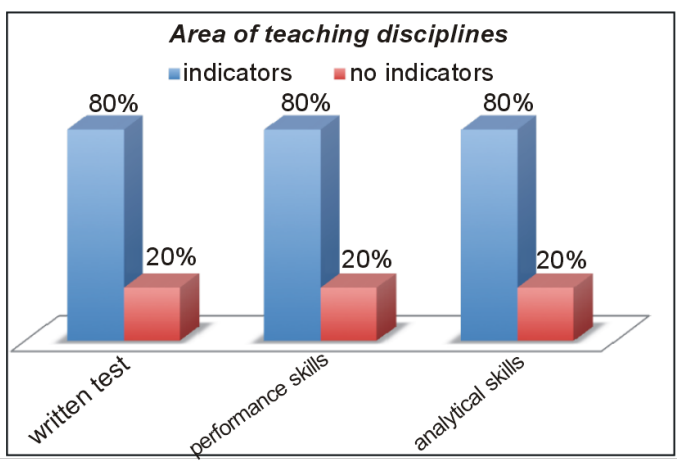

(d)

Figure 2. Entry exams in second level academic courses. 
On the side complementary to that of the norms we considered the concrete experience of the assessors: in the investigation into assessment between regulations and practices, considered opinions on experience as assessors were crucial, in a sample of 88 professors from 13 Conservatories representative of the variegated nature of higher musical institutions in Italy: the grand Conservatories of tradition, Conservatories of a more modest size, decentred Conservatories, Conservatories that depend administratively on local bodies, and recently founded Conservatories.

Analysis of the questionnaires completed by instrumental teachers in the chosen Conservatories expressed the relationship that these teachers feel they have with their specific roles within their institutions. This study was carried out using a written questionnaire consisting of 21 questions, both open and closed. The questions were of three basic types. The first three questions, of a general nature, defined the job profile and educational context in which the teacher works. The subsequent questions referred to the relationship between specific educational objectives and the assessment. The last part of the questionnaire concerned the idea of assessment as an activity where the function of the teacher is to implement institutional, national and international qualitative standards. The questions required the teacher to quantify his degree of awareness of this concept of assessment.

Examination of the data on the opinions of Conservatory professors who work as assessors, and the importance attributed to the qualitative indicators to be used normally for exams allowed us to bring to light:

1) existence of criteria shared between professors as regards exams

The first question asked teachers to choose 3 out of 8 evaluating criteria for exams and to allocate a decreasing grade of preference (from 3 to 1 ) to each; initial observation of the data considered which three criteria had been chosen by more than $50 \%$ of the professors with any value whatever (1, 2 or 3$): 57.95 \%$ of the professors opted for precision in decoding the musical text, $73.86 \%$ for expressive capacity and $85.22 \%$ technical skills (Figure 3);

2) existence of low percentages of agreement on the attribution of importance to assessment criteria and on the share ability of the assessment

Referring to the first question, we investigated what criteria are considered most important (value 3) to identify the real possibility of agreement in assessing: precision in decoding a written part was chosen as the most important criterion by $37.50 \%$ of the professors, expressive capacities by $28.40 \%$ and technical skills by $21.59 \%$ (Figure 4);

3) existence of self-referentiality in the perception of one's own professional profile

The professors in the sample were asked to choose one of three definitions of assessment, according to their personal experience.

One question proposed the following three definitions of assessment:

a) an educational issue which only concerns the teacher,

b) a duty based on shared criteria, agreed mutually,

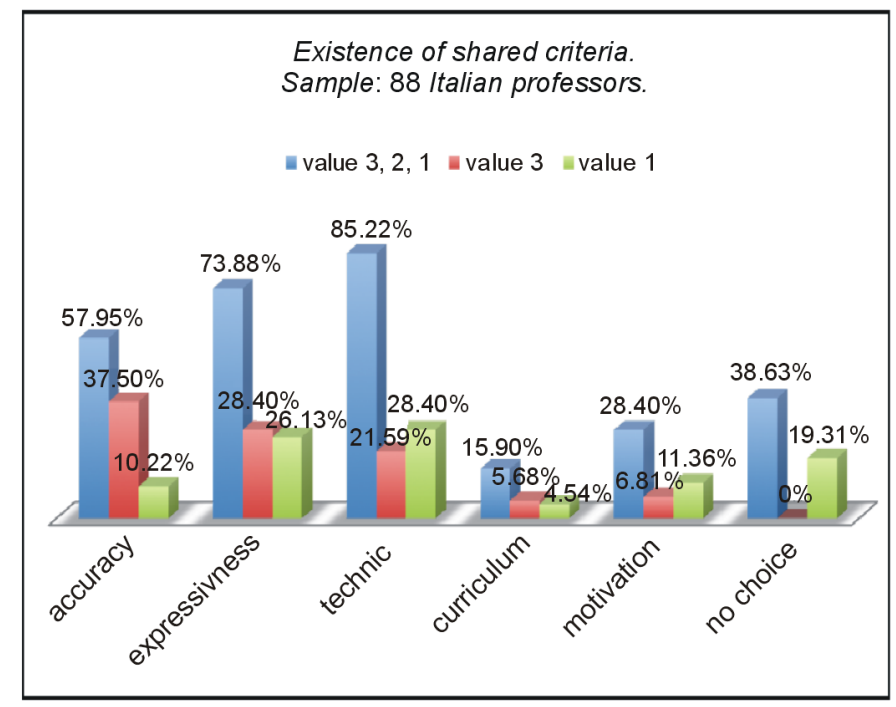

Figure 3. Existence of shared criteria. Sample: 88 Italian professors. 


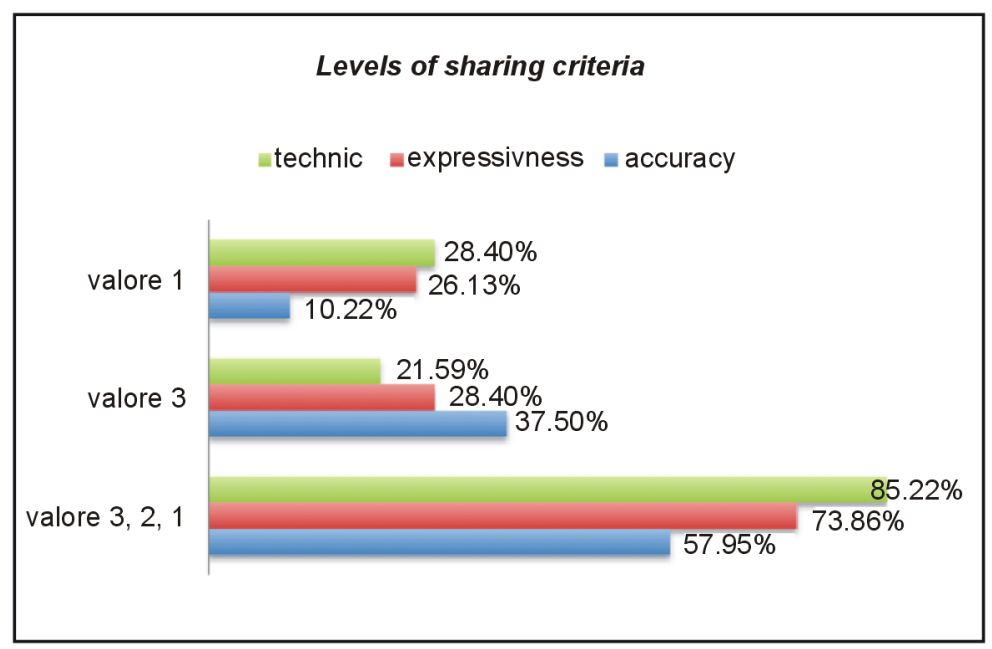

Figure 4. Levels of sharing criteria.

c) a duty which concerns institutional procedures and respects standard assessment levels (Figure 5).

Only $38.63 \%$ of the professors stated that assessment is an institutional mandate that guarantees quality standards, while all the others believed that assessment is a personal didactic question $(9.09 \%)$ or that it needs shared criteria established by mutual agreement among professors themselves (52.27\%).

In the area of Higher Musical Education in Italy provided by the Conservatories, it seems evident that the skill considered most important in an exam is still that of technical ability (85.22\%). This is followed by expressiveness (73.85\%) and precision in performance (57.85\%). This fact demonstrates that more than half the teachers agree on the criteria of technical ability, expressiveness and precision as the most important criteria in the assessment of musical performance.

On the data relating to how much these are relevant, however, there is less agreement and fewer than half the teachers agreed on the order of importance: in fact only $37.50 \%$ of the teachers rank precision in first place, while $28.40 \%$ indicate expressive capacity and $21.59 \%$ technical ability.

It is therefore obvious that agreement on assessment criteria can display strong critical points and lead to assessments that follow extemporaneous criteria that are not necessarily made plain. In fact, the percentage of teachers who stated that they refer to assessment criteria tacitly or reciprocally shared is significant (52.27\%), and indicates a procedural problem of major importance: are the criteria for assessing a student sufficiently transparent for both the examining Commissions and the students themselves at every stage-initial, intermediate and final? Unquestionably, further periodic studies to investigate the procedural and normative situation, involving institutions, teachers and students, could offer important information to improve the system as a whole.

\section{Assessment Practices and Tools}

It is the professor's duty to reflect on which assessment tools are most suitable in the concrete practice of teaching/learning, developing — despite the wide institutional indifference that characterizes the Italian situation in assessing learning in Conservatories-tools and procedures for assessment that transcend an extemporaneous personal judgement but are trustworthy and replicable, and at the same time flexible, so that they can be adapted to the contexts where they are to be used. The professor who can reflect in this sense can produce a real change in mentality and is pursuing the goal of promoting a profound renewal from within institutions.

We now intend to illustrate a tested practice considered replicable and designed by the first author of this article to measure students' achievements in specialist musical training at Conservatories in intermediate exams in pedagogical disciplines. It is intended to be a contribution-normally adopted by the author over the last five years, during her intermediate exams in didactic disciplines for the training of teachers, as a work tool to be shared among Commissions - towards a more transparent and efficient assessment of written and oral exams for use by Conservatory professors (also the tables presented have been drawn up by the author).

In accordance with the instructions of the AEC (Association Européen des Conservatoires, Académies de Musiqueet Musickhochschulen), when students receive a basic pedagogical training, whether in the I or II cycle, 


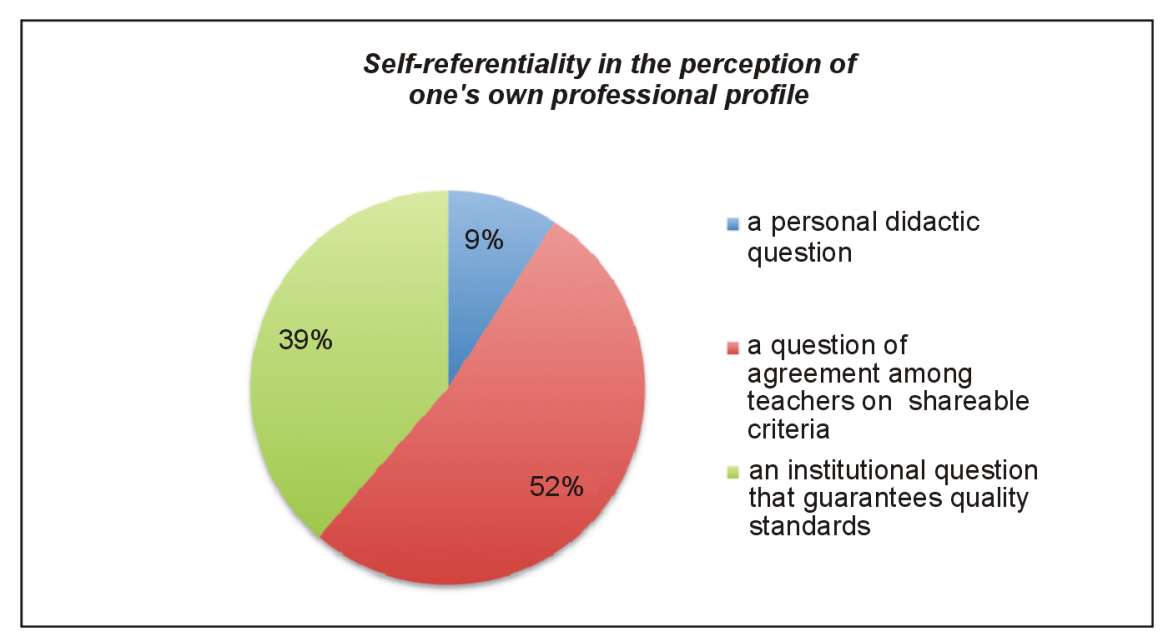

Figure 5. Self-referentiality in the perception of one’s own professional profile.

they should have learning outcomes of a theoretical variety—knowledge-based—and of a practical variety— skills-based-demonstrating that they:

a) know the interrelationships between their theoretical and practical studies;

b) are aware of how to use this knowledge to boost their personal artistic development;

c) have thorough understanding of pedagogical theory.

This tested practice proposes a model assessment form of students' ability to teach their main subject, or music in general, to other students of various levels, demonstrating that they are able to deal with the theory and practical application of pedagogical theories, also by means of multimedia documentation of the course attended, and of the demonstrable results.

Thus, this is an assessment of multiple skills by means of structured written or oral exams, also with practical or multimedia demonstrations, that highlights the expected didactic competence, and not an assessment of musical performance on an instrument and/or with the voice which are subject to a different kind of assessment (Rossi, 2012).

The ongoing development of the assessment form is based on assessment methodologies used in the international evaluations overseen by the IEA (International Association for the Evaluation of Educational Achievement) and employed as a model to put together new tests that include both a holistic assessment and an assessment of particular single aspects. It is part of the trend of studies already practised in Italy in scholastic assessment in general, and aims to represent a useful tool to stem subjectivity and support, also in Conservatories, a more correct culture of assessment open to international comparison (Corda Costa \& Visalberghi, 1995).

The assessment form being proposed locates and summarizes 2 elements - the quality of the knowledge content and the organisation and presentation of this content-that are the object being checked by means of overall and analytical assessments, thereby allowing the allocation of marks (depending on whether the results are Adequate, Partially Adequate, Not Adequate or Omitted) and an eventual expression of eligibility, or a mark expressed out of a scale of thirty as currently used (Figure 6 and Figure 7).

This answers, using minimal descriptors, the need to provide a survey tool—and to have some written record of the verdict of the assessment - that offers transparency, homogeneity, speed, replicability, and, at the same time, personalisation and fluidity in being able to embrace and respect:

a) the student's expressive style and creative contribution;

b) possible fluctuations in judgement of the board of assessors;

c) the aims and methods of the teaching in each single discipline and of each individual professor.

\section{Conclusions: Consistency in Assessment with an Assurance of Optimal Artistic Development of the Student}

The training of young musicians is measured internationally at levels formulated by the Dublin Descriptors and Learning Outcomes, and in constant confrontation with the European debate on assessment. 


\begin{tabular}{|l|r|}
\hline & No answer, incomprehensible 0 \\
\cline { 2 - 2 } frst impression * & Not adequate 1 \\
\cline { 2 - 2 } & Adequate 2 \\
\cline { 2 - 3 } & Excellent 3 \\
\cline { 2 - 3 }
\end{tabular}

\begin{tabular}{|c|c|c|}
\hline \multicolumn{3}{|l|}{ ANALYTICAL ASSESSUENT } \\
\hline \multirow{8}{*}{$\begin{array}{l}\text { Question } 1 \text { - TOPIC } \\
\text { PROPOSED BY THE BOARD }\end{array}$} & \multirow[b]{4}{*}{ KNOWLEDGE OF THE TOPIC } & No answer 0 \\
\hline & & Answer totally Nat Adequate 1 \\
\hline & & Answer partially Adequate 2 \\
\hline & & Answer Adequate 3 \\
\hline & \multirow{4}{*}{$\begin{array}{l}\text { EXPRESSIVE CAPACITY (ncluding CAPACITY } \\
\text { OF ANALYSIS, SYNTHESIS, RE- } \\
\text { ELABORATION) }\end{array}$} & No answer 0 \\
\hline & & Answer totally Nat Adequate 1 \\
\hline & & Answer partially Adequate 2 \\
\hline & & Answer Adequate 3 \\
\hline \multirow{8}{*}{$\begin{array}{l}\text { Question } 2 \text { - TOPIC } \\
\text { PROPOSED BY THE } \\
\text { CANDIDATE }\end{array}$} & \multirow[b]{4}{*}{ KNOWLEDGE OF THE TOPIC } & No answer 0 \\
\hline & & Answer totally Nat Adequate 1 \\
\hline & & Answer partially Adequate 2 \\
\hline & & Answer Adequate 3 \\
\hline & \multirow{4}{*}{$\begin{array}{l}\text { EXPRESSIVE CAPACITY (including CAPACITY } \\
\text { OF ANALYSIS, SYNTHESIS, RE- } \\
\text { ELABORATION) }\end{array}$} & No answer 0 \\
\hline & & Answer totally Not Adequate 1 \\
\hline & & Answer partially Adequate 2 \\
\hline & & Answer Adequate 3 \\
\hline \multirow{8}{*}{$\begin{array}{l}\text { Question 3- TOPIC PROPOSED } \\
\text { BY THE CANDIDATE and } \\
\text { SELECTED BY THE BOARD }\end{array}$} & \multirow[b]{4}{*}{ KNOWLEDGE OF THE TOPIC } & No answer 0 \\
\hline & & Answer totally Not Adequate 1 \\
\hline & & Answer partially Adequate 2 \\
\hline & & Answer Adequate 3 \\
\hline & \multirow{4}{*}{$\begin{array}{l}\text { EXPRESSIVE CAPACITY (including CAPACITY } \\
\text { OF ANALYSIS, SYNTHESIS, RE- } \\
\text { ELABORATION) }\end{array}$} & No answer 0 \\
\hline & & Answer totally Not Adequate 1 \\
\hline & & Answer partially Adequate 2 \\
\hline & & Answer Adequate 3 \\
\hline \multicolumn{3}{|c|}{ TOTAL SCORE } \\
\hline & UARK IN 30130 & \\
\hline
\end{tabular}

\section{Figure 6. Example of assessment form.}

The tasks of Conservatory professors as assessors are not and cannot be purely formal achievements and must permit a real comparability of qualifications, and guarantee students equality and equal opportunities in access to training, both during the acquisition of skills, and when entering the world of work.

Bringing the identity of each student to the fore, also at the moment of an assessment, represents an objective and a training investment, and must be able to be objectified.

In fact it is precisely objectivity that is penalized when each teacher can refer to a different personal objectivity, with consequences on assessment of the objective quality of the test, as far as the moment of the test itself is concerned, and with consequences on the comparative fairness that contextualizes assessment of a single test with analogous situations. 


\begin{tabular}{|c|c|c|}
\hline LEVEL OF MASTERY OF COMPETENCE & $\begin{array}{c}\text { ROUGH } \\
\text { SCORE }\end{array}$ & MARK \\
\hline TOTALLY NEGA TIVE & 12 & No votes \\
\hline UNCERTAIN & 13 & \\
\hline \multirow{13}{*}{ FAVOURABLE } & \multirow{2}{*}{14} & 18 \\
\hline & & 19 \\
\hline & \multirow{2}{*}{15} & 20 \\
\hline & & 21 \\
\hline & \multirow{2}{*}{16} & $\mathbf{2 2}$ \\
\hline & & 23 \\
\hline & \multirow{2}{*}{17} & 24 \\
\hline & & 25 \\
\hline & \multirow{2}{*}{18} & 26 \\
\hline & & 27 \\
\hline & \multirow{2}{*}{19} & $\mathbf{2 8}$ \\
\hline & & 29 \\
\hline & 20 & 30 \\
\hline PERFECT & 21 & 30R3O WITH HONOURS \\
\hline
\end{tabular}

Figure 7. Table showing relationship between score and mark expressed in 30/30.

Rigid structuring of study courses does not correspond to an equally rigid enunciation of professionalism inprofessors as assessor in guaranteeing the development of a student's artistic profile in an optimal way.

Professors should be offered the possibility to enhance their teaching capabilities, by supporting them via suitable training schemes before and during their working life, to clearly redefine their artistic and training responsibilities.

Certainly, successful training is not guaranteed by the efficacy of an assessment, however within the equilibrium of the teaching process, it is possible to systematize the problems and teaching prospects, and contribute to bringing out and developing a new professional awareness.

\section{References}

Ausubel, D. P. (1968). Educational Psychology. A Cognitive View. New York: Holt (tr. it.: 1983. Educazione e processi cognitivi. Milano: Franco Angeli).

Avanzini, A. (2002). Giuseppe Verdi, un profilo pedagogico. Milano: Franco Angeli.

Bordin, A., Cantamessa, M., \& De Cicco, D. (2012). Musical Learning and Assessment: Normatives, Practices and Methods in the Context of the Italian Education System. In T. S. Brophy, \& A. Lehmann-Wermser (Eds.), Music Assessment across Cultures and Continents: The Culture of Shared Practice. Proceedings of the 3rd International Symposium on Assessment in Music Education (pp. 175-185). Chicago: GIA Publication.

Conati, M. (2000). Ricordi personali su Verdi (1898-1900). In Verdi. Interviste e incontri (pp. 370-373). Torino: EDT.

Corda Costa, M., \& Visalberghi, A. (1995). Misurare e valutare le competenze linguistiche. Firenze: La Nuova Italia.

Cox, J. (2010). Admission and Assessment in Higher Music Education. Brussels: AEC-Association Européenne des Conservatoires Académies de Musiqueet Musikhochschulen.

Döbert, H., von Kopp, B., \& Mitter, W. (2007). The Education Systems of Europe. London: Springer.

Eurydice (2010). Focus on Higher Education in Europe 2010. The Impact of the Bologna Process. Brusselles: European Commission.

Fautley, M. (2010). Assessment in Music Education. Oxford: Oxford University Press.

Gatti, C. (1931). Verdi. Milano: Alpes. 
Montemorra Marvin, R. (2010). Verdi the Student-Verdi the Teacher. Parma: Istituto Nazionale di Studi Verdiani.

Oberdorfer, A. (1951). Giuseppe Verdi. Autobiografia dalle lettere. Milano: Rizzoli.

Pougin, A. (1881). Giuseppe Verdi. Vita anedottica, con note ed aggiunte di Folchetto. Milano: Ricordi.

Rossi, T. (1997). The Present Reality and Trends in Italian Music Education. In S. Leong (Ed.), Music in Schools and Teacher Education: A Global Perspective (pp. 229-236, 308-312). Nedlands: ISME, Callaway International Resource Centre for Music Education (CIRCME), The University of Western Australia.

Rossi, T., \& Fedrigo, C. (2010). Music Teaching Professions and New Teacher Training in Italian Conservatories of Music: From Music Educator to Teacher of Music and Instruments. In N. Kalyoncu, D. Erice, \& M. Akyuz (Eds.),. Music and Music Education within the Context of Socio-Cultural Changes. Proceedings of the 18th EAS Congress (pp. 215-223). Ankara: Abant Izzet Baysal University-EAS Association for Music in Schools.

Rossi, T., \& Fedrigo, C. (2012). The Musician as Teacher: A Contribution to Higher Musical Education in Italy. In Program and Conference Schedule, 20th EAS Conference, Craftsmanship \& Artistry (pp. 18-19). The Hague, The Netherlands: EAS Association for Music in Schools, The Royal Conservatoire The Hague.

Walker, F. (1962). The Man Verdi. London: Dent. (Reprint: Chicago: University of Chicago Press, 1982) 
Scientific Research Publishing (SCIRP) is one of the largest Open Access journal publishers. It is currently publishing more than 200 open access, online, peer-reviewed journals covering a wide range of academic disciplines. SCIRP serves the worldwide academic communities and contributes to the progress and application of science with its publication.

Other selected journals from SCIRP are listed as below. Submit your manuscript to us via either submit@scirp.org or Online Submission Portal.
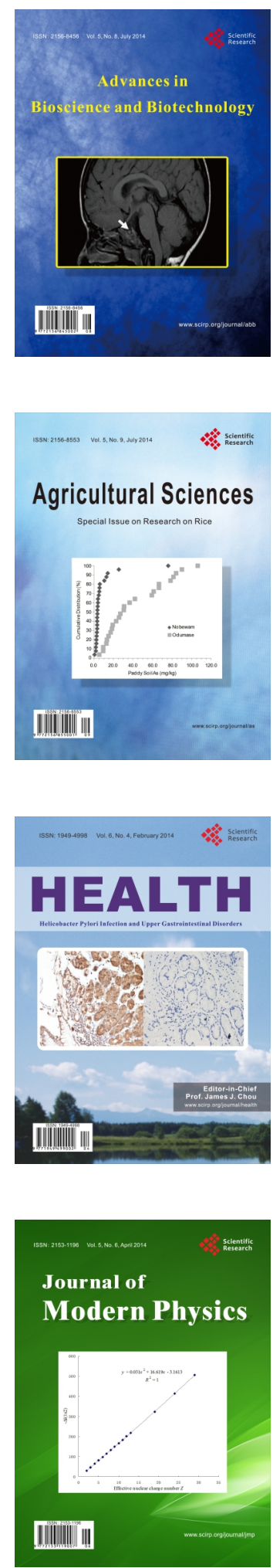
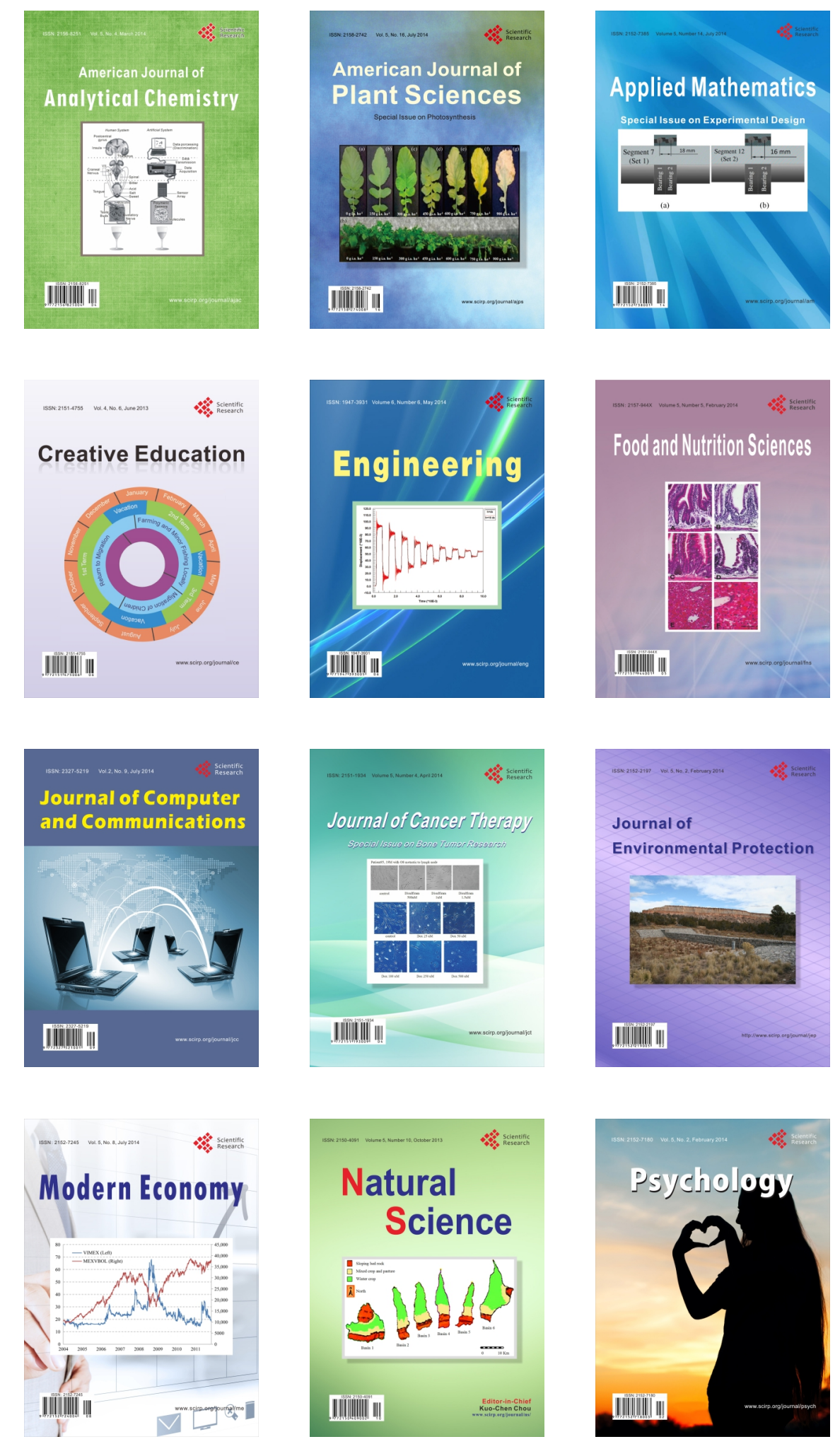